\title{
Stiffness of the large arteries in individuals with and without Down syndrome
}

\author{
This article was published in the following Dove Press journal: \\ Vascular Health and Risk Management \\ 8 June 2011 \\ Number of times this article has been viewed
}

\author{
Anabel N Rodrigues ${ }^{1,2}$ \\ Luan Cesar Coelho' \\ Washington LS Goncalves ${ }^{1,2}$ \\ Sonia Alves Gouvea ${ }^{2}$ \\ Maria José Rossi \\ Vasconcellos' \\ Roberto S Cunha ${ }^{2}$ \\ Glaucia R Abreu² \\ ISchool of Medicine, University \\ Center of Espírito Santo, Colatina; \\ ${ }^{2}$ Postgraduate Program in \\ Physiological Sciences, Center for \\ Health Sciences, Federal University \\ of Espirito Santo, Vitória, Brazil
}

Background: Down syndrome is known to cause premature aging in several organ systems. However, it remains unclear whether this aging effect also affects the structure and function of the large arterial trunks. In this controlled study, the possibility of changes in the large arteries due to aging was evaluated in patients with Down syndrome.

Methods: Eighty-two subjects of both genders were selected. The Down syndrome group had 41 active subjects consisting of 19 males and 22 females (mean age $21 \pm 1$, range 13-42 years) without cardiovascular complications and who did not use vasoactive drugs. The control group consisted of 41 healthy individuals without trisomy 21 of the same gender and age as the Down syndrome group and who did not use vasoactive medication. Carotid-femoral pulse wave velocity was obtained as an index of aortic stiffness using an automatic noninvasive method.

Results: Individuals with Down syndrome had significantly lower blood pressure than those in the control group. Systolic blood pressure for the Down syndrome group and control group was $106 \pm 2 \mathrm{mmHg}$ vs $117 \pm 2 \mathrm{mmHg}(P<0.001)$, respectively; diastolic blood pressure was $66 \pm 2 \mathrm{mmHg}$ vs $77 \pm 2 \mathrm{mmHg}(P<0.001)$; and mean arterial pressure was $80 \pm 1 \mathrm{mmHg}$ vs $90 \pm 1 \mathrm{mmHg}(P<0.001)$. Only age and systolic blood pressure were shown to correlate significantly with pulse wave velocity, but the slopes of the linear regression curves of these two variables showed no significant difference between the two study groups. Pulse wave velocity, which was initially significantly lower in the Down syndrome group $(7.51 \pm 0.14 \mathrm{~m} / \mathrm{s}$ vs $7.84 \pm 0.12 \mathrm{~m} / \mathrm{s} ; P<0.05$ ), was similar between the groups after systolic blood pressure adjustment $(7.62 \pm 0.13 \mathrm{~m} / \mathrm{s}$ vs $7.73 \pm 0.13 \mathrm{~m} / \mathrm{s})$.

Conclusion: Despite evidence in the literature that patients with Down syndrome undergo early aging, this process does not seem to affect the large arterial trunks, given that values of carotid-femoral pulse wave velocity were similar in individuals with or without trisomy 21 . Considering that Down syndrome presents with chronic hypotension, it is reasonable to propose that the prolonged reduction of arterial distending pressure may contribute to functional preservation of the arteries in patients with Down syndrome.

Keywords: aging, Down syndrome, pulse wave velocity, arterial stiffness

\section{Introduction}

The role of the large arterial trunks in the genesis, perpetuation, and aggravation of cardiovascular disease is accentuated in certain population groups, ${ }^{1-3}$ and high arterial stiffness has been described as an early marker of changes in arterial structure or asymptomatic atherosclerotic lesions. ${ }^{4,5}$

In recent years, there has been great interest in determining the effects of aging on the structure of the vascular system. Several mechanisms, including apoptosis ${ }^{6}$ and the telomeric hypothesis of cellular aging, have been proposed to influence such changes functionally or structurally. ${ }^{7,8}$ Studies also report that factors such as height, body mass index, and heart rate can influence the behavior of the large arteries. ${ }^{9-11}$ These changes
Correspondence: Anabel N Rodrigues School of Medicine of the University Center of Espírito Santo, Colatina, Brazil Tel/fax +55273723 3000

Email anabel@anabelnunes.org 
are similar to those observed in systemic arterial hypertension, which can mimic the accelerated aging of large arteries when maintained at high levels. ${ }^{6,9,12,13}$

Evidence in the literature suggests that Down syndrome has an early aging component. Because it is a segmental progeroid syndrome in adults, Down syndrome displays a number of the characteristics seen in the normal aging population, ${ }^{14}$ and the quality of organ systems function is directly associated with functional aging. ${ }^{15,16}$

It is necessary to determine to what extent genetic disorders such as Down syndrome cause global biologicalfunctional aging. The working hypothesis of this study was that individuals with Down syndrome could present with early structural and functional impairment of the large arteries. The purpose of this study was to determine if individuals with Down syndrome show changes in aortic distensibility measured in vivo using noninvasive carotidfemoral pulse wave velocity.

\section{Methods}

The ideal model for the study of biological aging would be to study patients with progeria, a condition that causes premature aging. In theory, if the number of beats in these individuals was essentially identical to the number of beats in a normal individual of the same age and there was increased aortic stiffness, a biological component could be implicated as a determinant of greater aortic rigidity. If aortic stiffness was identical in both groups, a hemodynamic component could be identified as a major determinant of aortic stiffness. However, the difficulty in finding individuals with progeria led our group to seek an alternative model, using individuals with trisomy 21 (Down syndrome), a population that is clearly progeroid and frequently described in the literature as a model for premature aging. ${ }^{17}$

In this study, 82 individuals of both genders were divided into two groups. One group consisted of 41 individuals with Down syndrome, aged 13-42 years. The control group consisted of 41 healthy individuals matched for gender and age range. Individuals and their legal guardians were invited to participate voluntarily in this study. After being informed about all relevant procedures and aspects of the study, participants signed an informed consent form in accordance with national and international standards for research conducted using human subjects. The study was approved by the Ethics in Human Research Committee of the Federal University of Espirito Santo.

A total of 41 individuals, comprising 22 females aged 14-42 years and 19 males aged 13-35 years were preselected for the control group. All individuals performed their daily activities without cardiovascular symptoms, and none of them used vasoactive drugs or other medications that could influence the results of the study.

A total of 41 individuals with Down syndrome, comprising 22 females aged 14-42 years and 19 males aged 13-35 years were selected. All individuals performed their daily activities at the Pestalozzi and Association of Parents and Friends of Exceptional Children societies in Espirito Santo, Brazil, and had laboratory confirmation of simple trisomy of chromosome 21 in their medical records. None of the individuals had clinical evidence of cardiovascular disease or a history of vasoactive drug use.

All individuals underwent a general and specific clinical examination, including cardiologic auscultation, anthropometric measurements (weight, height, waist, and hip) and recording of blood pressure. Conventional 12-lead electrocardiograms were performed, as well as echocardiograms to rule out any aortic valvulopathy or significant hemodynamic malformation. Echocardiography was performed using an ESAOTE $^{\circledR}$ machine (Esaote Biomedica, Bologna, Italy) and color flow mapping equipped with printers. Subjects were examined in the left lateral position at approximately $45^{\circ}$ by the same investigating cardiologist. Two patients with Down syndrome were replaced due to the finding of significant valvular lesions.

Weight $(\mathrm{kg})$ and height $(\mathrm{m})$ of the subjects in both groups were measured and recorded. Waist circumference at the umbilicus and hip height at the greater trochanter were also recorded. The waist-hip ratio was calculated as the waist circumference/hip circumference. Body mass index was calculated as weight $(\mathrm{kg}) /$ height $\left(\mathrm{m}^{2}\right)$.

Systolic and diastolic blood pressures in both groups were taken three times using a standard mercury sphygmomanometer. Systolic pressure was determined as the moment when the first sound of Phase I Korotkoff appeared, and diastolic pressure was determined as the disappearance of sound at Phase V Korotkoff. Patients rested seated for 5-10 minutes before the measurements were taken. None had consumed alcohol, coffee, or food, or had smoked or performed exercise 30 minutes prior to blood pressure measurement. Three measurements were performed every 1-2 minutes with the patient seated and the arm supported at heart level. If any of the diastolic blood pressure measurements had differences $>5 \mathrm{mmHg}$, new measurements were taken until the differences were below this value. The average of three measurements was used. Mean arterial pressure was calculated as $(2 \times$ diastolic 
blood pressure) + systolic blood pressure/3. Heart rate was calculated from the electrocardiographic recording.

Aortic distensibility was measured using a noninvasive automatic device according to methods previously described by Asmar et al, ${ }^{18}$ which consists of the simultaneous acquisition of digital acoustic signals in the carotid and femoral pulse and calculation of transit time. This methodology has been validated and was suitable for several reasons. Because easy wave registration is recorded at two points, the distance between these two points is large enough to allow for a safe calculation of the time interval between the two waves registered simultaneously on paper with a relatively high speed $(150 \mathrm{~mm} / \mathrm{s})$. In addition, carotid-femoral pulse wave velocity reflects the elasticity of the aorta. Carotid-femoral pulse wave velocity is calculated by measuring the distance (m) traveled between two recording points and the transit time (s) between two simultaneous recording sites, ie, pulse wave velocity $=$ distance carotid-femoral $(\mathrm{m}) /$ transit time $(\mathrm{s})$.

Pulse wave velocity was obtained at $500 \mathrm{~Hz}$ using two pressure transducers (TY-396, Fukuda Denshi Co, Tokyo, Japan) placed on the common carotid and right femoral vein and connected to an automatic processor $\left(\right.$ Complior $^{\circledR}$, Colson AS, Paris, France). When a pulse wave of sufficient quality and gain was registered, an automatic calculation of the time delay between the two points was made. The distance $(\mathrm{cm})$ between the two points was measured with a measuring tape. The average of five measurements of ten acquisitions was considered the pulse wave velocity for each individual.

\section{Statistical analysis}

Sample size calculation was performed using Statmate ${ }^{\circledR}$ software (v 2.0; GraphPad, San Diego, CA), which showed $\mathrm{n}=80$, with an estimated ideal sample test power of $90 \%$ and alpha error of 0.05 . To verify the differences between the average pulse wave velocity values of the two groups, a $t$-test was used for the two paired populations, as well as all other variables analyzed. Multivariate analysis and linear regression were performed to determine the main predictors of pulse wave velocity. Linear regression analyses between pulse wave velocity and systolic blood pressure and between pulse wave velocity and age were then used to evaluate the effects of systolic blood pressure and age on arterial stiffness. The slopes of the regression lines between systolic blood pressure and pulse wave velocity or age were compared using the $t$-test. The independent effects of systolic blood pressure and body mass index on pulse wave velocity were evaluated by analysis of covariance and adjusted. The new pulse wave velocity values for both groups after systolic blood pressure adjustment through analysis of covariance were compared. All results are shown as mean \pm standard error of the mean (SEM). The significance level was set at $P<0.05$.

\section{Results}

Table 1 shows the anthropometric and hemodynamic values for each group. With the exception of age and heart rate, there were significant differences $(P<0.05)$ between the studied variables (body mass index, systolic blood pressure, diastolic blood pressure, and waist-hip ratio) when comparing the subjects with Down syndrome and the controls.

Multilinear regression between age, systolic blood pressure and body mass index (index maintained due to population studies performed by the MONICA/World Health Organization, project in Vitória, Brazil, showing a positive correlation with this variable) demonstrated that only age and systolic blood pressure were significantly $(P<0.05)$ related to pulse wave velocity, as shown in Table 2 .

Figure 1 shows the linear regression models using Pearson's correlation coefficient for age (Figure 1A), systolic blood pressure (Figure 1B), and carotid-femoral pulse wave velocity in the two groups. In the $t$-test for comparison between the linear regression curves, we found no significant differences in slope $(b \pm \mathrm{SEM})$ for pulse wave velocity and age (Figure 1A) between the groups (Down syndrome group $0.065 \pm 0.019 \mathrm{~m} / \mathrm{s} /$ year vs control group $0.038 \pm 0.018 \mathrm{~m} / \mathrm{s} /$ year; $P=0.31$, not significant) and or between pulse wave velocity and systolic blood pressure (Down syndrome group $0.033 \pm 0.012$ vs control group $0.026 \pm 0.012 \mathrm{mmHg}, P=0.68$, not significant, Figure 1B).

Table I Anthropometric and hemodynamic characteristics in the experimental groups

\begin{tabular}{llll}
\hline & Down syndrome & Controls & P-value \\
\hline Age (years) & $2 \mathrm{I} \pm \mathrm{I}$ & $2 \mathrm{I} \pm \mathrm{I}$ & - \\
Variance & $(\mathrm{I} 3-42)$ & $(\mathrm{I}-42)$ & \\
Weight $(\mathrm{kg})$ & $55 \pm 2$ & $6 \mathrm{I} \pm 2$ & $<0.05$ \\
Height $(\mathrm{m})$ & $1.47 \pm 0.0 \mathrm{I}$ & $\mathrm{I} .64 \pm 0.0 \mathrm{I}$ & $<0.00 \mathrm{I}$ \\
BMI $\left(\mathrm{kg} / \mathrm{m}^{2}\right)$ & $25 \pm \mathrm{I}$ & $22 \pm \mathrm{I}$ & $<0.0 \mathrm{I}$ \\
WHR & $0.88 \pm 0.0 \mathrm{I}$ & $0.80 \pm 0.0 \mathrm{I}$ & $<0.00 \mathrm{I}$ \\
SBP $(\mathrm{mmHg})$ & $106 \pm 2$ & $1 \mathrm{I} \pm 2$ & $<0.00 \mathrm{I}$ \\
DBP $(\mathrm{mmHg})$ & $66 \pm 2$ & $77 \pm 2$ & $<0.00 \mathrm{I}$ \\
MAP $(\mathrm{mmHg})$ & $80 \pm \mathrm{I}$ & $90 \pm \mathrm{I}$ & $<0.00 \mathrm{I}$ \\
HR $(\mathrm{bpm})$ & $74 \pm 2$ & $76 \pm 2$ & $\mathrm{NS}$ \\
PWV $(\mathrm{m} / \mathrm{s})$ & $7.5 \mathrm{I} \pm 0.14$ & $7.84 \pm 0.12$ & $<0.05$ \\
\hline Note $\mathrm{Dat}$ & & &
\end{tabular}

Note: Data are expressed as mean \pm standard error.

Abbreviations: bpm, beats per minute; DS, Down syndrome; BMI, body mass index; WHR, waist-hip ratio; SBP, systolic blood pressure; DBP, diastolic blood pressure; MAP, mean arterial pressure; HR, heart rate; PW, pulse wave velocity; NS, not significant. 
Table 2 Multivariate linear regression with Pearson's correlation of factors associated with carotid-femoral pulse wave velocity in controls and subjects with Down syndrome

\begin{tabular}{llll}
\hline & Coefficient & Correlation & $P$-value \\
\hline Constant & 2.937 & - & $<0.01$ \\
Age (years) & $0.05 \mathrm{I}$ & 0.385 & $<0.00 \mathrm{I}$ \\
$\mathrm{BMI}\left(\mathrm{kg} / \mathrm{m}^{2}\right)$ & 0.012 & 0.076 & $\mathrm{NS}$ \\
SBP $(\mathrm{mmHg})$ & 0.030 & 0.413 & $<0.00 \mathrm{I}$ \\
\hline
\end{tabular}

Abbreviations: BMI, body mass index; SBP, systolic blood pressure; NS, not significant.

Analysis of covariance showed a significant $(P<0.05)$ effect only for systolic blood pressure and pulse wave velocity, but this difference disappeared after systolic blood pressure was adjusted, as shown in Table 3 .

\section{Discussion}

The most significant finding in this study was that individuals with Down syndrome do not have higher aortic stiffness
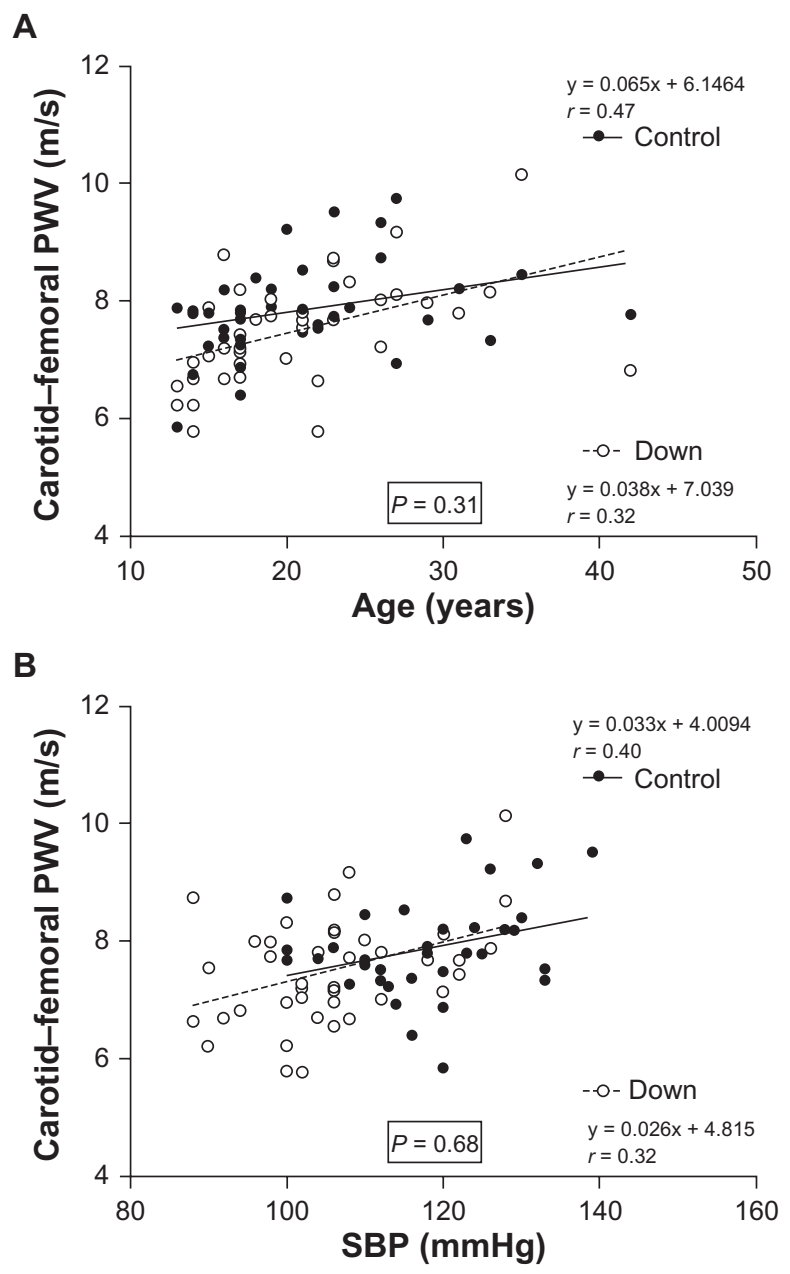

Figure I Multivariate linear regression model with Pearson's correlation coefficient between age, systolic blood pressure, and carotid-femoral pulse wave velocity in controls and subjects with Down syndrome.
Table 3 Analysis of covariance between carotid-femoral pulse wave velocity values in controls and subjects with Down syndrome before and after adjustment of systolic blood pressure

\begin{tabular}{llll}
\hline & Down syndrome & Control & P-value \\
\hline Age (years) & $2 \mathrm{I} \pm \mathrm{I}$ & $2 \mathrm{I} \pm \mathrm{I}$ & - \\
Variance & $(\mathrm{I}-42)$ & $(13-42)$ & - \\
$\mathrm{PWV}(\mathrm{m} / \mathrm{s})$ & $7.5 \mathrm{I} \pm 0.14$ & $7.84 \pm 0.12$ & 0.045 \\
Adjusted PWV $(\mathrm{m} / \mathrm{s})$ & $7.62 \pm 0.13$ & $7.73 \pm 0.13$ & 0.577 \\
\hline
\end{tabular}

Abbreviation: PWV, pulse wave velocity.

values than individuals of the same age and gender without trisomy 21. All evidence described to date suggests that Down syndrome would be a good model for premature aging. ${ }^{14-16}$ However, some studies have found few atherosclerotic lesions and a low frequency of cardiovascular disease, ${ }^{19-21}$ small amounts of calcium in the arteries, ${ }^{22}$ and possible protection against development of atherosclerosis, due to increased antioxidant activity of superoxide dismutase in people with Down syndrome. ${ }^{23}$ Our study showed that carotid-femoral pulse wave velocity in these individuals was significantly lower than in a control group, but that after systolic blood pressure adjustment, the statistical significance of these values disappeared. This suggests that the accelerated aging described in other organ systems in Down syndrome does not occur in the aorta, confirming previous reports in the literature that indicate that the process of aging is accompanied by an increase in pulse wave velocity. 24,25

Several theories have been proposed to explain aging, including random mutations in the DNA of somatic cells, cross-linking between collagen fibers and some proteins, cumulative tissue damage due to free radicals, ${ }^{26}$ and, more recently, the telomere hypothesis. ${ }^{27}$ However, no consensus has been achieved regarding our understanding of the aging process.

The search for mechanisms that lead to appropriate growth have dominated scientific research for a long time. However, there is limited knowledge about the aging process, which is a period that dominates most of the lifespan, and we still have no representative biomarkers of aging that enable us to define accurate physiological age in humans. ${ }^{28}$

Although the mechanisms are still debated, the manifestations of aging have been well described. Identification of early structural and hemodynamic changes with the aim of identifying factors that may trigger the process, slow it, and attenuate or block it when already in progress are still needed. Although a convention for characterizing arterial stiffness $^{29}$ has not yet been established, arterial stiffness has been significantly correlated with aging. An increase in 
arterial stiffness can serve as an early marker of asymptomatic atherosclerotic lesions and/or structural changes due to hypertension. ${ }^{30}$ Studies using pulse wave velocity, a widely accepted index of arterial stiffness, have made the assessment of arterial distensibility possible in various population groups and these have been compared with more invasive measures. ${ }^{18,31-34}$

In the general population, it is well established that aging is characterized by dilatation and progressive increase in stiffness of the large arteries, and that age and blood pressure are independent determinants of aging. However, there has been nothing published about the status of the large arteries in people with Down syndrome, who frequently present with segmented characteristics of premature aging, but now have an increased life expectancy.

In this study, we compared the anthropometric and hemodynamic characteristics of individuals having Down syndrome with those in age-matched and gender-matched individuals without trisomy 21 . In addition, quantitative information about the large arteries of controls and subjects with Down syndrome was obtained by pulse wave velocity, as previously described by Asmar et al, ${ }^{18}$ and compared, enabling indirect evaluation of distensibility and arterial stiffness. To avoid possible confounding influences due to gender and age, all individuals in the Down syndrome group were age-matched and gender-matched with the controls. ${ }^{9,12,35}$

In population studies, obesity has received special attention as an important risk factor for cardiovascular disease, where weight gain increases the risk in both men and women, and has been correlated with pulse wave velocity. ${ }^{36}$ Although obesity is not a consequence of Down syndrome, ${ }^{37}$ more than half of the children affected by this syndrome are overweight. The evidence for weight excess in our sample was suggested by body mass index and waist-hip ratio, and values for both variables were significantly greater than in the control group. The significantly higher weight in the control group might be explained by the mean greater stature of individuals not suffering from Down syndrome. In population studies (MONICA/World Health Organization project, Vitoria, Brazil), body mass index has been significantly correlated with pulse wave velocity, although this was not observed in our study, most likely due to the small sample size.

Aging is a determinant of vascular stiffening, and has been shown to be an independent predictor of pulse wave velocity. ${ }^{14,18,38}$ In our study, individuals were age-matched and gender-matched, and adjustments in this respect were not considered. Increases in pulse wave velocity in relation to age have been reported in all studies conducted so far. After linear regression analysis, this was also evident in our work, as shown in Figure 1A. To evaluate the effect of age on aortic stiffness in both groups, the slope of the regression curves for pulse wave velocity and age were compared, suggesting that age had a similar effect in both groups.

A close relationship has been demonstrated between pulse wave velocity and hemodynamic factors. Elevated cardiac frequency has been associated with higher pulse wave velocity and low arterial distension, and is a good predictor of cardiovascular morbidity. ${ }^{12,39}$ Cardiac frequency has been positively associated with several risk factors (eg, dyslipidemia, glycemia, physical inactivity) and arterial hypertension in particular..$^{40}$ In our study, no significant difference in cardiac frequency was observed between the two groups. It is important to note that studies have shown deleterious effects of mechanical stress on the intimal layers of the arteries and that this can be offset by reducing cardiac frequency. ${ }^{11,31,38}$

Systemic hypertension has been associated with hypertrophy and hyperplasia of arterial smooth muscle as well as increased collagen synthesis, and has been acknowledged as one of the major risk factors for cardiovascular disease. Several studies have correlated congestive heart failure, stroke, chronic renal failure, and coronary disease with systemic hypertension, and the need for its reduction is already a global consensus. Additionally, the literature has shown that hypertension seems to accelerate aging of the cardiovascular system due to decreased release of endothelial nitric oxide, ${ }^{28}$ alterations in arterial wall composition, and decreased functional distensibility of the large arteries, all of which contribute to greater stress in the arterial wall. ${ }^{41}$

Systolic blood pressure values and age have been reported as the most important predictors of vascular aging in all the relevant studies reported to date. Our study showed that pulse wave velocity (Table 1) was significantly lower in the Down syndrome group before systolic blood pressure value adjustment. After adjustment, carotid-femoral pulse wave velocity between the two groups became similar and no longer statistically significant (Table 3 and Figure 1B). This finding confirms the importance of blood pressure as a determinant of arterial stiffness, generating a greater or lesser degree of hemodynamic stress. There is no evidence of premature aging of the arterial tree in subjects with Down syndrome of the same age and gender.

Systolic, diastolic, and mean arterial pressures were significantly lower in patients with Down syndrome (Table 1). These data are consistent with studies performed by Richards and Enver ${ }^{42}$ who showed lower blood pressure in patients 
with Down syndrome in all age ranges from 5 years onwards, and are similar to those of Down syndrome patients with a mean age of 3.57 years in a study performed by Russo et al. ${ }^{43}$ Other studies ${ }^{11,18,31,38}$ have shown a correlation between pulse wave velocity and systolic blood pressure, where higher blood pressure leads to greater pulse wave velocity and consequently greater arterial stiffness, as shown in the linear regression between carotid-femoral pulse wave velocity and systolic blood pressure for both groups evaluated in this study (Table 2). Analysis of the linear regression showed no significant difference in the effects of blood pressure on the mechanical properties of the vessels (Figure 1B), suggesting an equal influence of this variable in both the Down syndrome and control groups.

Increased pulse wave velocity is associated with dilatation and stiffening of the large vessels, and these characteristics accompanied the aging process and the similar influence of age and systolic blood pressure on aortic stiffness in both groups. Our findings allow us to state that there is no evidence of premature aging of the arterial tree in patients with Down syndrome, a condition which can be described as a form of progeria. Our results suggest that systolic blood pressure is an independent predictor of pulse wave velocity and that individuals with Down syndrome show lower values than people without trisomy 21 . This may have a lower impact on the endothelium of the blood vessels and result in a lower turnover of cells, thereby causing lower vascular telomere wear and contributing to slower aging of the system.

Despite all the issues raised in the literature involving premature aging of individuals with Down syndrome, ${ }^{14-16}$ our results indicate that these individuals show no premature aging of their arterial vessels. It can be speculated that hypotension, a characteristic of this syndrome, attenuates the possible genetic effects that could contribute to accelerated aging of the vascular system. Although speculative, there is the possibility that maintaining low blood pressure levels may slow the aging process of the vascular system, which is the goal of any antihypertensive therapy.

\section{Acknowledgment}

This study was supported by a grant from CEPEG-UNESC.

\section{Disclosure}

The authors report no conflicts of interest in this work.

\section{References}

1. Safar ME, Toto-Moukou JJ, Bouthier JA, et al. Arterial dynamics, cardiac hypertrophy, and antihypertensive treatment. Circulation. 1987;75: 156-161.
2. Safar ME. Therapeutic trials and large arteries in hypertension. $A m$ Heart J. 1988; 115:702-710.

3. Safar ME, London G, Asmar RG, et al. Recent advances on large arteries in hypertension. Hypertension. 1998;32:156-161.

4. Blacher J, Asmar R, Djane S, et al. Aortic pulse velocity as a marker of cardiovascular risk in hypertensive patients. Hypertension. 1999;33: 1111-1117.

5. Lehmann ED. Clinical value of aortic pulse-wave velocity measurement. Lancet. 1999;354:528-529.

6. Hamet P, Thorin-Trescasesn N, Moreau P, et al. Excess growth and apoptosis. Is hypertension a case of accelerated aging of cardiovascular cells? Hypertension. 2001;37:760-766.

7. Von Zglinicki T. Telomeres: Influencing the rate of aging. Ann $N Y$ Acad Sci. 1998;854:318-327.

8. Reddel RR. A reassessment of the telomere hypothesis of senescence. BioEssays. 1998;20:977-984.

9. Cunha RS, Benetos A, Laurent S, Safar ME, Asmar RG. Distension capacity of the carotid artery and ambulatory blood pressure monitoring: Effects of age and hypertension. Am J Hypertens. 1995;8:343-352.

10. Smulyan H, Marchais SJ, Pannier B, et al. Influence of body height on pulsatile arterial hemodynamic data. J Am Coll Cardiol. 1998;31: 1103-1109.

11. Avolio A, Jones D, Tafazzoli-Shadpour M. Quantification of alterations in structure and function of elastin in the arterial media. Hypertension. 1998;32:170-175.

12. Cunha RS, Dabire H, Bezie Y, et al. Mechanical stress of the carotid artery at the early phase of spontaneous hypertension in rats. Hypertension. 1997;29:992-998.

13. Lakatta EG. Arterial pressure and aging. Int J Cardiol. 1989;25: S81-S89.

14. Nakamura E, Tanaka S. Biological ages of adult men and women with Down's syndrome and its changes with aging. MechAgeing Dev. 1998; 105: 89-103.

15. Comfort A. Test-battery to measure ageing-rate in man. Lancet. 1969;27:1411-1415.

16. Hofecker G, Skalicky M, Kment A, et al. Models of the biological age of the rat. I. A factor model of age parameters. Mech Ageing Dev. 1980;14:345-359.

17. Haynes A, Batshaw M. Down syndrome. Pediatr Clin North Am. 1993;40:523-535.

18. Asmar R, Benetos A, Topouchian J, et al. Assessment of arterial distensibility by automatic pulse wave velocity measurement. Hypertension. 1995;26:485-490.

19. Murdoch JC, Roger JCH, Rao SS, et al. Down syndrome: An atheroma free model? Br Med J. 1977;2:226-228.

20. Morrison RA, McGrath A, Davidson G, et al. Low blood pressure in Down's syndrome, a link with Alzheimer's disease? Hypertension. 1996;28:569-575.

21. Yang Q, Rasmussem SA, Friedman JM, et al. Mortality associated with Down's syndrome in the USA from 1983 to 1997: A population-based study. Lancet. 2002;359:1019-1025.

22. Yla-Herttuala S, Luoma J, Nikkari T, et al. Down syndrome and atherosclerosis. Atherosclerosis. 1989;76:269-272.

23. Goyal P, Singh R, Yadav A, et al. Dyslipidemia and superoxide dismutase activity in children with Down syndrome. J Nepal Pediatr Soc. 2010;30:160-163.

24. Bortolotto LA, Blacher J, Kondo T, et al. Assessment of vascular aging and atherosclerosis in hypertensive subjects: Second derivative of photoplethysmogram versus pulse wave velocity. Am J Hypertens. 2000;13:165-171.

25. Lehman ED. Noninvasive measurements of aortic stiffness: Methodological considerations. Pathol Biol (Paris). 1999;47:716-730. French.

26. Ganong WF. Review of Medical Physiology. 17th ed. East Norwalk, CT: Appleton and Lange; 1995.

27. Osiewacz HD, Hamann A. DNA reorganization and biological aging. A review. Biochemistry (Mosc). 1997;62:1275-1284. 
28. Folkow B, Svanborg A. Physiology of cardiovascular aging. Physiol Rev.1993;73:725-764.

29. O'Rourke MF, Mancia G. Arterial stiffness. J Hypertens. 1999; $17: 1-4$.

30. Arnett DK, Evans GW, Riley WA. Arterial stiffness: A new cardiovascular risk factor? Am J Epidemiol. 1994;140:669-682.

31. Avoilo AP, Fa-quan D, Wei-Quiang L, et al. Effects of aging on arterial distensibility in populations with high and low prevalence of hypertension comparison between urban and rural communities in China. Circulation. 1985;71:202-210.

32. Bland J, Altman G. Statistical methods for assessing agreement between two methods of clinical measurement. Lancet. 1986;88: 307-322.

33. Benetos A, Topouchian J, Richard S, et al. Influence of angiotensin II type 1 receptor polymorphism on aortic stiffness in never treated hypertensive patients. Hypertension. 1995;26:44-47.

34. Benetos A, Gautier S, Richard S. Influence of angiotensin II type 1 receptor gene polymorphism on aortic stiffness in normotensive and hypertensive patients. Circulation. 1996;94:698-703.

35. London GM, Guerin AP, Pannier B, et al. Influence of sex on arterial hemodynamics and blood pressure. Role of body-height. Hypertension. 1995;26:514-519.
36. Toto-Moukouo JJ, Achimastos A, Asmar RG, et al. Pulse wave velocity in patients with obesity and hypertension. Am Heart J. 1986;1120: 136-140.

37. Sharav T, Bowman T. Dietary practices, physical activity, and body-mass index in a selected population of Down syndrome children and their siblings. Clin Pediatr. 1992;31:341-344.

38. Avolio A. Genetic and environmental factors in the function and structure of the arterial wall. Hypertension. 1995;26:34-37.

39. Benetos A, Rudnichi A, Safar M, Guize L. Pulse pressure and cardiovascular mortality in normotensive and hypertensive subjects. Hypertension. 1999;32:560-564.

40. Morcet JF, Safar M, Thomas F, et al. Associations between rate and other risk factors in a large French population. J Hypertens. 1999;17: 1671-1676.

41. London GM, Safar ME. Arterial wall remodeling and stiffness in hypertension: Heterogeneous aspects. Clin Exp Pharmacol Physiol. 1996;23:S1-S5.

42. Richards BW, Enver F. Blood pressure in Down's syndrome. J Ment Defic Res. 1979;23:123-133.

43. Russo MA, Pacileo G, Marino B, et al. Echocardiographic evaluation of left ventricular systolic function in the Down syndrome. Am J Cardiol. 1998;81:1215-1217.
Vascular Health and Risk Management

\section{Publish your work in this journal}

Vascular Health and Risk Management is an international, peerreviewed journal of therapeutics and risk management, focusing on concise rapid reporting of clinical studies on the processes involved in the maintenance of vascular health; the monitoring, prevention and treatment of vascular disease and its sequelae; and the involvement of

\section{Dovepress}

metabolic disorders, particularly diabetes. This journal is indexed on PubMed Central and MedLine. The manuscript management system is completely online and includes a very quick and fair peer-review system, which is all easy to use. Visit http://www.dovepress.com/ testimonials.php to read real quotes from published authors. 